\title{
A cross-sectional study to assess the adverse effect profile of second generation antipsychotics: risperidone, olanzapine and quetiapine
}

\author{
Scandashree K. ${ }^{1}$, Praveenkumar B. ${ }^{2}$, Padmaja Udaykumar ${ }^{3} *$
}

${ }^{1}$ Department of Pharmacology, Mysore Medical College and Research Institute, Mysore, India

${ }^{2}$ General physician and pharmacology, Vidyagiri, Ballari, Karnataka, India, ${ }^{3}$ Department of Pharmacology, Father Muller Medical College, Mangalore, India

Received: 16 August 2016 Accepted: 20 August 2016

\section{*Correspondence to:}

Dr. Padmaja Udaykumar, Email: padmajaudaykumar @gmail.com

Copyright: (C) the author(s), publisher and licensee Medip Academy. This is an openaccess article distributed under the terms of the Creative Commons Attribution NonCommercial License, which permits unrestricted noncommercial use, distribution, and reproduction in any medium, provided the original work is properly cited.

\begin{abstract}
Background: Pharmacovigilance is the scientific approach to a drug related problem. Psychotropic drugs are known to cause several adverse drug reactions (ADRs). This study aimed to assess the adverse effect profile of 3 second generation antipsychotics-risperidone, olanzapine and quetiapine in patients on monotherapy of any of these second generation antipsychotics.

Methods: This was a hospital based cross-sectional study conducted in psychiatric outpatient department of Psychiatry in Father Muller Mental Health Centre, Mangalore. The study sample consisted of patients suffering from schizophrenia and other psychotic disorders according to ICD 10 criteria (F20F29) and who were maintaining remission on any one of the second generation antipsychotics viz risperidone, olanzapine or quetiapine.

Results: Out of 154 subjects, 68 were on risperidone, 74 were on olanzapine, and 12 were on quetiapine. Most common ADRs reported were increased appetite $(26 \%)$, weight gain $(15 \%)$, tremors $(14 \%)$, fatigue $(14 \%)$, constipation (14\%), dyspepsia (10\%), somnolence $(12 \%)$, decreased appetite $(10 \%)$. Among these ADRs none of them were preventable and belonged to mild to moderate severity. Causality of adverse events was assessed by Naranjo algorithm; a probability scale for ADR. Severity was assessed by modified Hartwig and Seigel scale. Preventability was assessed using Schumock and Thronton criteria. Conclusions: The most common ADRSs reported with SGAs were increased appetite and weight gain and the frequency of ADRs were higher with subjects receiving risperidone.
\end{abstract}

Keywords: Second generation antipsychotics, Adverse drug reactions, Pharmacovigilance

\section{INTRODUCTION}

ADRs are a major clinical problem as evident from many clinical studies and account for about 2-6\% of all hospital admissions. ADRs can increase the cost of patient care and length of hospital stay. ${ }^{1}$ Scientifically approaching a drug related problem is considered as pharmacovigilance. Its role is to discover, quantify and document drug related problems, contribute to decrease the risk of drug related problems in health care systems and to increase the knowledge of understanding of factors and mechanisms responsible for drug related problems.
Pharmacoepidemiological methods are used in pharmacovigilance and they tend to be either 'Hypothesis-generating methods' like spontaneous ADR reporting and prescription event monitoring or 'Hypothesis-testing methods' like case control studies, cohort studies and randomized controlled studies. ${ }^{2}$

Post marketing surveillance is an essential component in assessing drug safety and tolerability. Many of the unknown serious ADRs have been recognized in several short term trials after the drug has been marketed. Among them some drugs are withdrawn and some drugs contain 
a boxed warning by FDA regarding the possible deleterious event. Remoxipride was an antipsychotic marketed in 1980s which had shown efficacy similar to haloperidol with less extrapyramidal symptoms. Later its tendency to cause aplastic anaemia came to light in Europe after which it was withdrawn in $1993{ }^{3}$ Some of the antipsychotics that have been specified to issue boxed warning are: a) Asenapine: For the Risk of Serious Allergic Reactions. ${ }^{4}$ b) Aripiprazole, Quetiapine, and Olanzapine when used along with Fluoxetine: Risk of Suicidality. ${ }^{5,6}$ c) Second generation antipsychotics used in elderly patients with dementia-risk of increased mortality. $^{7-9}$ d) Delirium and sedation with olanzapine pamoate injection. ${ }^{10}$ e) With clozapine- risk of agranulocytosis, orthostatic hypotension, bradycardia, and syncope. ${ }^{11}$

Second generation (atypical) antipsychotics (SGAs): Currently available SGA drugs are Clozapine (the first atypical antipsychotic drug that was approved by FDA in 1989), risperidone, olanzapine, quetiapine, ziprasidone, aripiprazole, asenapine, sertindole, zotepine, paliperidone, iloperidone, and sulpiride. Clozapine is considered the prototype of this group as it has all characteristics of an atypical drug. 12 General characteristics of second generationantipsychotics include 1. Less EPS or movement disorders including tardive dyskinesia at doses necessary to produce an antipsychotic effect. 2. Efficacy against both the negative and positive symptoms of schizophrenia 3. Fewer effect on prolactin elevation. 4. The SGA drugs also have a higher ratio of 5$\mathrm{HT}_{2}$ to $\mathrm{D}_{2}$ blockade compared to the FGA drugs. ${ }^{12}$

Risperidone belongs to the chemical class of benzisoxazoles. It was the second atypical antipsychotic to be introduced into the US market and is extensively used. It has affinity for $\mathrm{D}_{2}$ and $5-\mathrm{HT}_{2} \mathrm{~A}$ receptors, adrenergic and histamine $\mathrm{H} 1$ receptors. ${ }^{13}$ Olanzapine is a dibenzodiazepine compound and is antagonistic at both the $\mathrm{D}_{2}$ and $5-\mathrm{HT}_{2} \mathrm{~A}$ receptors, but is stronger on $\mathrm{D}_{2}$ receptors. 106 A dosage of $10-20 \mathrm{mg} /$ day results in 71$80 \%$ of D2 receptor "occupancy," while $30 \mathrm{mg} /$ day results in a superior occupancy $(>80 \%)$, because of which there is increased incidence of extra pyramidal side effects at higher doses. 107 Olanzapine also binds to histamine $\left(\mathrm{H}_{1}\right)$, adrenergic (alfa1) and various dopaminergic receptors. ${ }^{14}$ Quetiapine is a dibenzothiazepine compound. It has a greater affinity for $5-\mathrm{HT}_{2}$ receptors than for $\mathrm{D}_{2}$ receptors; also has an affinity for $\mathrm{H}_{1}$ and alpha 1 and alpha 2 adrenergic receptors. The low $\mathrm{D}_{2}$ affinity is the cause for a reduced incidence of extra pyramidal side effects. ${ }^{15}$

There are many studies done to know the adverse effect profile of first generation antipsychotics in Indian population. But second generation antipsychotics have a different spectrum of receptor specificity which results in a different adverse effect profile also. This study aims at comparing the adverse effect profile of three second generation antipsychotics which were on monotherapy of risperidone, olanzapine and quetiapine.

\section{METHODS}

\section{Study centre}

This study was conducted at the psychiatry out-patient department of the father Muller mental health Centre, Mangalore. This was a cross sectional, hospital based, comparative study.

\section{Study population}

The study sample consisted of patients suffering from schizophrenia and other psychotic disorders according to ICD 10 criteria (F20- F29) and who were maintaining remission on any one of the second generationantipsychotics viz risperidone, olanzapine or quetiapine. Patients who were attending the Out Patient Department for their regular follow up were enrolled into the study, after obtaining the written consent.

\section{Inclusion criteria}

All the patients of age group 18-60 years, diagnosed with schizophrenia and other psychotic disorders (ICD$10 ;$ F20- F29), patients who are on any one of the second generation antipsychotic- either risperidone, olanzapine, or quetiapine for at least 4 weeks duration.

\section{Exclusion criteria}

Acute or severe psychotic state including delirium, dementia and other cognitive disorders, patients with sensory impairment, patients who were unwilling to participate in the study.

\section{Method of data collection}

After obtaining the Institutional Ethics Committee clearance, the 154 subjects were recruited for the study after obtaining their written informed consent. Details regarding the demographic data, illness history, and details regarding the current antipsychotic treatment. After collecting the required socio-demographic and clinical data, adverse effects were assessed using UKU side effect scale. Causality of adverse events was assessed by Naranjo algorithm; a probability scale for ADR. ${ }^{16}$ Severity was assessed by modified Hartwig and Seigel scale. ${ }^{17}$ Preventability was assessed using Schumock and Thronton criteria. ${ }^{18,19}$

The study sample consisted of 154 patients who were divided into three groups; Group1- receiving risperidone only, Group 2- receiving olanzapine only and Group 3receiving quetiapine only. 


\section{Statistical analysis}

The statistical analysis of data was performed using SPSS for Windows (version 19.0) and Microsoft Excel. Descriptive statistics used for the means and frequencies of socio-demographic and clinical data of the study population.

\section{RESULTS}

Out of 154 subjects, 68 were on risperidone, 74 were on olanzapine, and 12 were on quetiapine. The mean age of subjects recruited in the study was between 36-38 years. The group matching was even with respect to variables, such as, age, gender, and CPZ equivalent doses between 3 groups. Out of 156 ADRs that were reported among 154 patients, 67 were due to risperidone, 57 were due to olanzapine and 32 were due to quetiapine. Most common ADRs reported were increased appetite (26\%), weight gain $(15 \%)$, tremors $(14 \%)$, fatigue $(14 \%)$, constipation (14\%), dyspepsia (10\%), somnolence $(12 \%)$, decreased appetite $(10 \%)$.

Frequency of adverse effects in the study subjects is shown in the pie graph. Causality assessment of adverse effects done using Naranjo algorithm is shown in the table 1. Increased appetite (was present in 26 subjects) was the most common adverse effect observed in the study subjects and was common (20 subjects) in olanzapine treated patients.

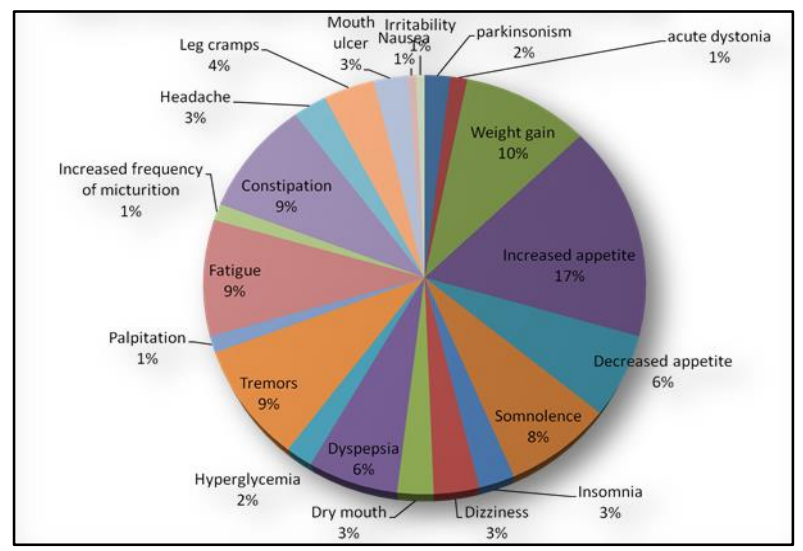

Figure 1: Adverse effect profile among study subjects.

Causality assessment revealed that 143 ADRs belonged to probable category and 13 ADRs belonged to possible category according Naranjo algorithm. No case could be labeled "certain" as rechallenge was not done. Severity was assessed by modified Hartwig and Seigel scale. There were no fatal or life threatening events and none required hospitalization. Preventability was assessed using Schumock and Thronton criteria and none of the ADRs were preventable.

Table 1: Causality assessment of adverse effects seen in the study subjects.

\begin{tabular}{|c|c|c|c|c|}
\hline Probability & Adverse Effects & Risperidone $\mathrm{n}=68$ & Olanzapine $n=74$ & Quetiapine $n=12$ \\
\hline \multirow{16}{*}{ Probable } & Parkinsonism & 2 & 1 & 0 \\
\hline & Acute Dystonia & 2 & 0 & 0 \\
\hline & Weight Gain & 4 & 10 & 1 \\
\hline & Increased Appetite & 6 & 20 & 0 \\
\hline & Decreased Appetite & 7 & 0 & 3 \\
\hline & Somnolence & 4 & 1 & 7 \\
\hline & Insomnia & 3 & 1 & 0 \\
\hline & Dizziness & 1 & 0 & 4 \\
\hline & Dry Mouth & 0 & 0 & 4 \\
\hline & Dyspepsia & 5 & 4 & 1 \\
\hline & Hyperglycemia & 2 & 1 & 0 \\
\hline & Tremors & 5 & 5 & 4 \\
\hline & Palpitation & 0 & 2 & 0 \\
\hline & Fatigue & 9 & 3 & 2 \\
\hline & Increased frequency of micturition & 1 & 1 & 0 \\
\hline & Constipation & 6 & 3 & 5 \\
\hline \multirow{6}{*}{ Possible } & Headache & 2 & 1 & 1 \\
\hline & Leg Cramps & 5 & 1 & 0 \\
\hline & Mouth Ulcer & 2 & 2 & 0 \\
\hline & Nausea & 0 & 1 & 0 \\
\hline & Irritability & 1 & 0 & 0 \\
\hline & Total & $67(\%)$ & $57(\%)$ & $32(\%)$ \\
\hline
\end{tabular}




\section{DISCUSSION}

Our study for assessment of ADRs of second generation antipsychotics was based on surveillance using a checklist in addition to the ADRs spontaneously reported by patients. The spontaneous reporting by the patients was poor but reporting rate was high when subjects they were asked about them.

According to literature and previous studies, the most common adverse effects with first generation antipsychotics were sedation, hypotention, extrapyramidal side effects and anticholinergic side effects. ${ }^{20}$ Although risperidone may share some of the adverse effects seen with FGAs, the incidence and severity of such effects may vary. Risperidone is reported to be less likely to cause sedation or extrapyramidal effects but agitation may occur more frequently. Other common adverse effects include insomnia, anxiety, headache, dyspepsia, nausea and vomiting, abdominal pain, constipation, blurred vision, sexual dysfunction including priapism, urinary incontinence, rash and other allergic reactions, drowsiness, concentration difficulties, dizziness, fatigue, and rhinitis have been reported less commonly. Other adverse effects include cerebrovascular accidents, tachycardia, weight gain, edema, increased liver enzymes. ${ }^{13}$ However, in the Clinical Antipsychotic Trials of Intervention Effectiveness (CATIE) study; it was the only one of the antipsychotic drugs studied that was associated with hyperprolactinemia. ${ }^{21}$ The rates of extrapyramidal side effects are comparable with those of some of the other SGAs, but patients taking doses greater than $6 \mathrm{mg} /$ day may experience significant extrapyramidal side effects and it has a low propensity to cause anticholinergic side effects. There is increased risk of death with the use of second generation antipsychotics in elderly patients with dementia related psychosis. ${ }^{22}$

The most common side effects of olanzapine are weight gain and somnolence. Hyperprolactinaemia, orthostatic hypotension, hyperglycemia, increased appetite, dizziness, fatigue, elevated triglyceride and liver enzyme values, edema, dry mouth and constipation are also quite common. It is associated with low incidence of extra pyramidal side effects including tardive dyskinesia. 23 Prominent side effects of quetiapine include sedation, tachycardia, and agitation. Due to its low affinity for D2 receptors, extra pyramidal effects are rare. Other common adverse effects include weight gain particularly during early treatment, and rise in plasma triglyceride and total cholesterol concentrations. ${ }^{24}$ Mild asthenia, anxiety, irritability, fever, rhinitis, peripheral edema, increased appetite, constipation, dyspepsia and dry mouth and raised liver enzymes. Leucopenia, neutropenia, thrombocytopenia, and eosinophilia have been reported. ${ }^{25}$

A Brazilian study analyzed 219 notifications of suspected ADRs of psychoactive medications and incriminated antipsychotics and antidepressants were the commonest group responsible for ADRs. ${ }^{26}$ But a Bulgarian study reported that the ADR frequency of individual psychotropic drugs studied is less than $1 \% .^{27} \mathrm{~A}$ knowledge, attitude and practice based study conducted in Norway found that ADRs can be prevented by collecting reliable information about their frequencies and possible risk factors. ${ }^{28}$

Total number of ADRs reported were156 from 154 subjects; 67 were due to risperidone, 57 were due to olanzapine and 32 were due to quetiapine. Most common ADRs reported were increased appetite $(26 \%)$, weight gain $(15 \%)$, tremors $(14 \%)$, fatigue $(14 \%)$, constipation (14\%), dyspepsia (10\%), somnolence $(12 \%)$, decreased appetite $(10 \%)$. Increased appetite and weight gain were the most common ADRs from the study subjects. Weight gain was seen in all the groups but most commonly with olanzapine and Decreased appetite was more common with risperidone. Weight gain can be a disincentive to comply with treatment and complicates comorbid medical conditions such as obesity and heart diseases.

Causality assessment according to Naranjo algorithm revealed that 143 ADRs were probable/likely and 13 were possible. Certainty could not be assessed as rechallenge was not done. There were no fatal or life threatening events and none required hospitalization. Most of the ADRs were of mild to moderate grade according to severity assessment. Among the ADRs reported in our study none of the ADR was preventable according to the preventability assessment by Schumock and Thronton criteria. The highest contribution of ADRs was from quetiapine receiving subjects. Regarding the drugs responsible for 156 ADRs among 154 patients, risperidone accounted for highest number of ADRs followed by olanzapine and quetiapine. Limitations of the study: This was a single centre, cross sectional study. Quetiapine monotherapy subjects recruited were too little.

\section{CONCLUSION}

This study results showed that there are many adverse effects these second generation antipsychotics can cause and treating physicians should be vigilant on the occurrence of adverse effects in SGA receiving patients. Future studies in the same area mandates larger sample size and randomized control trials to compare the profile between the drugs.

\section{Funding: No funding sources \\ Conflict of interest: None declared \\ Ethical approval: The study was approved by the Institutional Ethics Committee}

\section{REFERENCES}

1. Dhikav V, Singh S, Anand KS. Adverse drug reaction monitoring in India. JIACM. 2004;5(1):2733.

2. Chatterjee A, Sharma M, Gupta SK. Current Methods of Pharmcovigilance. In: Gupta SK, editor. 
Textbook of Pharmacovigilance. New Dehli. Jaypee Brothers Medical Publishers; 2011.

3. Fung M, Thornton A, Mybeck K, Hsiao-Hui J, Hornbuckle K, Muniz E. Evaluation of the characteristics of safety withdrawal of prescription drugs from worldwide pharmaceutical markets1960 to 1999. Drug Inf J. 2001;35:293-317.

4. U.S. Department of Health and Human Services. U.S. Food and Drug Administration. (2011, September 1). FDA Drug Safety Communication: Serious Allergic Reactions Reported with the Use of Saphris (asenapine maleate), at: http://www.fda.gov/Drugs/DrugSafety/ucm270243.h tm. Accessed on 18 July, 2014.

5. U.S. Department of Health and Human Services. U.S. Food and Drug Administration, 2009. Labeling Change Request Letter for Antidepressant Medications. Available at http://www.fda.gov/Drugs/DrugSafety/Informationb yDrugClass/ucm096352.htm. Accessed on 18 July, 2014.

6. Abilify® (aripiprazole) prescribing information. (2011, February). From http://www.accessdata.fda.gov/drugsatfda_docs/labe 1/2011/021436s032,021866s019,021713s024,021729 s017lbl.pdf . Retrieved July 18, 2014

7. U.S. Department of Health and Human Services. U.S. Food and Drug Administration, 2005. Public Health Advisory: Deaths with Antipsychotics in Elderly Patients with Behavioral Disturbances. Available at, http://www.fda.gov/Drugs/DrugSafety/PostmarketDr ugSafetyInformationforPatientsandProviders/DrugSa fetyInformationforHeathcareProfessionals/PublicHe althAdvisories/ucm053171.htm. Accessed on 18 July, 2014.

8. Gill SS, Bronskill SE, Normand SL, Anderson GM, Sykora K, Lam K, et al. Antipsychotic drug use and mortality in older adults with dementia. Ann Intern Med. 2007;146(11):775-86.

9. Schneeweiss S, Setoguchi S, Brookhart A, Dormuth C, Wang PS. Risk of death associated with the use of conventional versus atypical antipsychotic drugs among elderly patients. CMAJ. 2007;176(5):627-32. Erratum in: CMAJ. 2007;176(11):1613.

10. Relprevv Z. (olanzapine pamoate) prescribing information. Available at http://www.accessdata.fda.gov/drugsatfda_docs/labe 1/2009/022173lbl.pdf. Accessed on 18 July, 2014.

11. Clozaril (clozapine) prescribing information. (2013, March), Available at http://www.accessdata.fda.gov/drugsatfda_docs/labe 1/2013/019758s069s071lbl.pdf. Accessed on 18 July, 2014

12. Meltzer H. Antipsychotic agents \& Lithium. In: Katzung BG, Masters SB, Trevor AJ, editors. Basic $\&$ Clinical Pharmacology. $12^{\text {th }}$ edition. New Dehli: Tata McGraw-Hill;2012:502-3.

13. Risperidone. Sweetman SC. editor. Martindale The Complete Drug Regference. $37^{\text {th }}$ edition. London: Pharceutical Press;2011:1130-1133.
14. Divac N, Prostran M, Jakovcevski I, Cerovac N Second-generation antipsychotics and extrapyramidal adverse effects. Biomed Res Int. 2014;2014:656370.

15. Mathews M, Muzina DJ. Atypical antipsychotics: new drugs, new challenges. Cleve Clin J Med. 2007;74(8):597-606.

16. Naranjo CA, Busto U, Sellers EM, Sandor P, Ruiz I, Roberts EA, et al. A method for estimating the probability of adverse drug reactions. Clin Pharmacol Ther. 1981;30:239-45.

17. Schumock GT, Thornton JP. Focusing on the preventability of adverse drug reactions. Hosp Pharm. 1992;27:538.

18. Hartwig SC, Siegel J, Schneider PJ. Preventability and severity assessment in reporting adverse drug reactions. Am J Hosp Pharm. 1992;49:2229-32.

19. Mrugank BP and Hareesha RP. Prospective observational, non-randomized, parallel sequence study for assessment of adverse drug reactions due to chemotherapeutic treatment in different types of cancer patients. Int J Pharm Sci Res. 2013:4(1);38691.

20. Meyer JM. Pharmacotherapy of Psychosis and Mania. In: Bruton LL. editor. Goodman and Gilman's The Pharmacological Basis of Therapeutics, 12th edition. New York: Mc Graw Hill;2011:427.

21. Lieberman JA, Stroup TS, McEvoy JP, Swartz MS, Rosenheck RA, Perkins DO, et al. Clinical Antipsychotic Trials of Intervention Effectiveness (CATIE) Investigators. Effectiveness of antipsychotic drugs in patients with chronic schizophrenia. N Engl J Med. 2005;353(12):120923.

22. Schneider LS, Dagerman KS, Insel P. Risk of death with atypical antipsychotic drug treatment for dementia: meta-analysis of randomized placebocontrolled trials. JAMA. 2005;294(15):1934-43.

23. Olanzapine. Sweetman SC. editor. Martindale The Complete Drug Reference. 37th edition. London:Pharceutical Press; 2011:1117-1120

24. Quetiapine. Sweetman SC. editor. Martindale: The Complete Drug Reference. $37^{\text {th }}$ edition. London: Pharceutical Press; 2011:1128-1130.

25. Shankar BR. Quetiapine-induced leucopenia and thrombocytopenia. Psychosomatics. 2007;48(6):5301.

26. Carlini EL, Nappo SA. The pharmacovigilance of psychoactive medications in Brazil. Rev Bras Psiquiatr. 2003;25(4):200-5.

27. Dimitrova Z, Doma A, Petkova V, Getov I, Verkkunen E. Psychotropic drugs in Bulgariafrequency and risk of adverse drug reactions. Boll Chim Farm. 2002;141(1):75-9.

28. Castberg I, Reimers A, Sandvik P, Aamo TO, Spigset O. Adverse drug reactions of antidepressants and antipsychotics: experience, knowledge and attitudes among Norwegian psychiatrists. Nord J Psychiatry. 2006;60(3):227-33.

Cite this article as: Scandashree $\mathrm{K}$, Praveenkumar B, Udaykumar P. A cross-sectional study to assess the adverse effect profile of second generation antipsychotics: risperidone, olanzapine and quetiapine. Int J Basic Clin Pharmacol 2016;5:1785-9. 